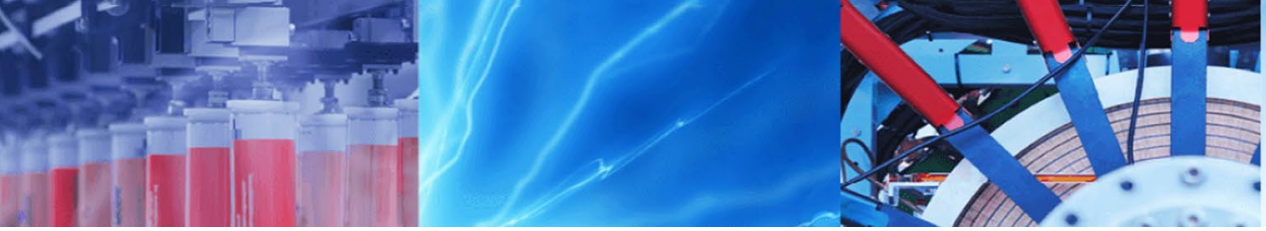

Research Article

\title{
Features of modeling the system of turbine unit with a variable contact zone of its stator parts
}

\author{
S. V. Krasnikov ${ }^{1}$ (1)
}

Received: 21 October 2020 / Accepted: 23 August 2021

Published online: 06 September 2021

(c) The Author(s) 2021 OPEN

\begin{abstract}
Modeling of stator parts of power units of thermal and nuclear power plants is carried out according to several standard schemes. Common methods of modeling systems with non-uniform and non-stationary contact of stator elements lead to significant errors in calculating the amplitudes of forced vibration displacement at a given external load. The object of this paper is to analyze errors in calculating the displacement amplitudes of forced oscillations in different modeling schemes according to the standard approach and developing a method for constructing a quasi-dynamic model taking into account the time-varying contact of the system's stator parts as well as other factors. To do this, the author has developed a series of models with different degrees of sampling and considering different system factors. Particular attention is paid to the impact of factors arising from the long operation of the power plant (subsidence of foundation). The modeling was carried out taking into account the calculation method. The finite element method was used to perform calculations. The results of the calculation of forced oscillation displacement amplitudes are available to show the areas of application of different types of three-dimensional models of the steam power unit. The results of research conducted on the developed models show the impossibility of using standard simulation schemes for systems with a variable contact between its stator elements, as shown by the example of a power unit with steam turbine. The efficiency of using the models taking into account the variable contact between the stator parts and other factors to calculate the displacement amplitudes of the forced oscillations with high accuracy is likewise presented. Every specialist should be aware of the factors that influence the research results. This paper is concerned with assessment of the influence of a number of factors on the results of calculating the vibrations of a complex mechanical system.
\end{abstract}

\section{Article Highlights}

- The basic (common) and five specific models of the turbine-foundation-base system are presented.

- Based on the results of calculations of forced vibrations, the credibility of each specific model is shown.
- The results of using the technique for modeling the optimal design scheme for turbines with a capacity of $300 \mathrm{MW}$ are shown.

Keywords Turbine unit · Steam power system · Forced vibration · Credibility of models · Finite element method

S. V. Krasnikov, vsevakr@ya.ru | ${ }^{1}$ Kharkiv National Automobile and Highway University, 25 Yaroslava Mudrogo st, Kharkov, Ukraine. 


\section{Introduction}

Modern civilization exists due to the stable operation of power plants [1]. The performance of power units depends on many factors. First of all, it is the vibration levels of its parts - the stator and rotor [2]. Many studies have focused on rotor oscillations [3-5]. This is primarily due to history. The fact is that reliable models of rotary systems can be developed with a small number of degrees of freedom. Also, these models, due to their simplicity, have increased possibilities for taking into account various nonlinear features $[6,7]$. However, the vibration characteristics and performance of the rotors depend primarily on the stator elements. Some researchers are trying to get away from this problem by rigidening the stator [8]. However, many studies show the impossibility of such an approach for real serial designs $[9,10]$. Even for sufficiently rigid supports of the rotor and the stator itself, their rigidity decreases over time [11]. This process leads to the appearance of undesirable contacts between the elements of the system, a change in the characteristics of friction $[12,13]$. The general consequence of insufficient consideration of the real stator stiffness is an increase in the values of vibration characteristics, including abruptly $[10,12,13]$. The study of oscillations of stator elements has many difficulties [14, 15]. However, in the study of current issues without the three-dimensional modeling of stator elements is impossible [16-18]. This is due to the fact that in any simulation of the rotor machines, the stiffener elements, such as the rotor supports and the bearing mounting points, must be considered. Many authors [16-24] are engaged in modeling and research of stator elements of power units. However, their studies do not always provide reliable results or are sufficient to address issues of vibration and system reliability. Therefore, many authors consider the vibrational reliability of the system from the power unit by different specific methods. Among them are the methods of experimental direction and numerical calculations. An advantage of experimental methods is the ability to obtain accurate data in real time $[25,26]$. Experimental tools focus primarily on vibration diagnostics [27-30]. Numerical calculations of the specific direction focus on the use of reliability theory and systems theory [31-34]. There are also quite specific methods using artificial intelligence methods [27, 30]. The disadvantage of many numerical methods is the need to obtain results from specific experimental studies. The disadvantage of experimental research is the high cost and other difficulties [35]. For example, about stopping and starting the power unit in an emergency mode or outside the work schedule. All these difficulties can be avoided with the help of the new models and methods of vibration study of power units offered in this article.
The article consists of 6 parts: introduction, analysis stages, types of 3D models and their construction, analysis of forced oscillations, discussion, conclusions.

The second section (Analysis stages) consists of two subsections: mathematical model, methods of model analysis and purpose of the study.

The third section consists of 8 subsections, which provide a detailed description of the base model with a check of its discretization, as well as six different models of the system under study.

The fourth section (Analysis of forced oscillations) consists of two subsections: models without foundation subsidence, models taking into account subsidence of foundation columns.

In discussion directions for increasing the accuracy of results and the realism of models are described.

\section{Analysis stages}

\subsection{Mathematical model}

Let's determine the system's variable parameters through the vector $\{S\}$. The vector $\{S\}$ consists of the components of three stiffnesses of the turbine connection with the foundation in three directions ( $X, Y, Z)$. In fact, the vector $\{S\}$ is a system of springs that connect the turbine to the foundation or the foundation itself is modeled. More details on the above said are given in Sect. 3.3 (Simplified model), and the springs themselves (a small part of them) are shown in Fig. 7.

The Lagrange equation of the second kind, known to all physicists, taking into account the vector $\{S\}$, is written in the following form:

$\frac{d}{d t}\left(\frac{\partial L(\{S\}, \dot{q}, q)}{\partial \dot{q}_{j}}\right)-\frac{\partial L(\{S\}, \dot{q}, q)}{\partial q_{j}}=0$,

where $\dot{q}_{j}$ is the generalized velocity along the $j$ generalized coordinate, $q_{j}$ is the generalized displacement along the $j$ generalized coordinate, $L(\{S\}, \dot{q}, q)$ is the Lagrange function, which is the difference between the kinetic $T$ and potential $P$ energies:

$L(\{S\}, \dot{q}, q)=T-P$.

For a specific study, the number of Lagrange equations of the second kind corresponds to the number of generalized coordinates. Lagrange equations of the second kind all together form a system of differential equations.

Notation of kinetic energy in matrix form: 
$T=0.5\{\dot{q}\}^{T}[M(\{S\})]\{\dot{q}\}$,

where $\{\dot{q}\}$ is the vector of generalized velocities, $[M(\{S\})]$ is the mass matrix.

Notation of the potential energy in matrix form: where $[M(\{S\})]$ is the matrix of masses; $\left[H\left(n_{j}\right)\right]$ is the damping matrix; $\left[C_{D}\right]$ and $[C(\{S\})]$ are determined and variable stiffness matrix; $\{S\}$ is the vector of system variable parameters; $\{R(t)\}$ is the vector of loads.

The displacement $\{q(t)\}$ and the load $\{R(t)\}$ vectors for

$P=0.5\{q\}^{T}\left[C_{D}+C(\{S\})\right]\{q\}-\{q\}^{T}\{R(t)\}-\{q\}^{T}\left\{R^{\prime}(t)\right\}+\{q\}^{T}\left\{R^{H}(t)\right\}$,

where $\{q\}$ is the vector of generalized displacements, $\left[C_{D}\right]$ and $[C(\{S\})]$ is determined and variable stiffness matrix, $\{R(t)\}$ is the vector of generalized external forces, $\left\{R^{\prime}(t)\right\}$ is the vector of generalized internal forces, $\left\{R^{H}(t)\right\}$ is the vector of dissipative forces.

The vector of dissipative forces $\left\{R^{H}(t)\right\}$ is traditionally written through the multiplication of the damping matrix $[H]$ by the vector of generalized velocities $\{\dot{q}\}$

$$
\left\{R^{H}(t)\right\}=\left[H\left(n_{j}\right)\right]\{\dot{q}\} .
$$

The most common ways to define the damping matrix $[H]$ are the Rayleigh method and the modal method. Both methods include a number of constants that are determined experimentally or based on the recommendations of the reference literature. It is more convenient to use the modal method, since more reference literature can be used for it. In particular, as the damping coefficients, it is possible for the simplest cases; one can use the data on the coefficients of materials friction known from the high-school physics course. In this study, a modal method
Eq. (6) are represented by:

$\{q(t)\}=\{V\} e^{i p t},\{R(t)\}=\left\{R_{0}\right\} e^{i \omega t}$,

where $p$ is the system's natural frequency; $\omega$ is the frequency of the forced load.

Taking into account (7), the equations for determining the natural frequencies and forms are as follows:

$\operatorname{det}\left[\left[C_{D}+C(\{S\})\right]-p_{j}^{2}[M(\{S\})]\right]=0$,

$\left[\left[C_{D}+C(\{S\})\right]-p_{j}^{2}[M(\{S\})]\right]\left\{V_{j}\right\}=0$,

where $p_{j}$ is the $j$-th natural frequency of the system; $\{V j\}$ is the vector of the $j$-th eigenmode of the system.

The natural frequencies and shapes were calculated using the iteration method in the subspace [37, 38]. The eigenform vectors $\{V j\}$ are combined together to form the eigenform matrix [V]. The matrix of eigenforms $[\mathrm{V}]$ is normalized in such a way that the following relations are fulfilled:

$[V]^{T}[M(\{S\})][V]=[I],[V]^{T}\left[C_{D}+C(\{S\})\right][V]=\left\{p^{2}\right\}^{T}[I][V]^{T}\left[H\left(n_{j}\right)\right][V]=\{2 p n\}^{T}[I]$,

for specifying the damping matrix $[H]$ has been distinguished. The reference values which are determined by the type of material and the type of construction are used as the coefficients $n_{j}$ of the damping matrix $[H]$ in the first approximation.

As a result of the fact that the parameters of the connection between the turbine and the foundation $\{S\}$ significantly affect the total moments of the turbine inertia, foundation and the entire system, the vector $\{S\}$ is the parameters of the mass matrix and the stiffness matrix. Since we have adopted to use modal friction in the calculations, the vector $\{S\}$ in the general case is not included in the matrix $[H]$.

After substituting expressions (3) - (5) into (2) and substituting (2) into (1), we obtain the general equation for motion (6) according to the finite element method [36]:

$[M(\{S\})]\{\ddot{q}\}+\left[H\left(n_{j}\right)\right]\{\dot{q}\}+\left[C_{D}+C(\{S\})\right]\{q\}=\{R(t)\}$, where $[I]$ is the identity matrix, $\left\{p^{2}\right\}$ is the vector of natural frequencies, $\{2 p n\}$ is the vector of multiplications of natural frequencies and damping matrix coefficients.

The computations of displacement of forced oscillations were performed using the method of decomposition according to their eigenforms.

$\{q(t)\}=[V]\{A(t)\}$,

Substituting (11) in (6):

$[M(\{S\})][V]\{\ddot{A}\}+\left[H\left(n_{j}\right)\right][V]\{\dot{A}\}+\left[C_{D}+C(\{S\})\right][V]\{A\}=\{R(t)\}$,

Multipling both parts $[V]^{T}$ : 
$[V]^{T}[M(\{S\})][V]\{\ddot{A}\}+[V]^{T}\left[H\left(n_{j}\right)\right][V]\{\dot{A}\}+[V]^{T}\left[C_{D}+C(\{S\})\right][V]\{A\}=[V]^{T}\{R(t)\}$,

Considering (7) and (10), we obtain:

$[I]\{\ddot{A}\}+\{2 p n\}^{T}[I]\{\dot{A}\}+\left[p^{2}\right]^{T}[I]\{A\}=[V]^{T}\left\{R_{0}\right\} e^{i \omega t}$,

We will seek a solution in the form of the right side:

$\{A(t)\}=\{A(\{S\}, \omega)\} e^{i \omega t}$,

where $\{A(\{S\}, \omega)\}$ is the vector of the displacement amplitudes of forced oscillations.

Substituting (15) in (14) and grouping, we obtain:

$\left[-\omega^{2}[I]+i \omega\{2 p n\}^{T}[I]+\left\{p^{2}\right\}^{T}[I]\right]\{A(\{S\}, \omega)\} e^{i \omega t}=[V]^{T}\left\{R_{0}\right\} e^{i \omega t}$,

It can be seen that by reduction by $e^{i \omega t}$ one can get rid of the time dependence:

$\left[-\omega^{2}[I]+i \omega\{2 p n\}^{T}[I]+\left\{p^{2}\right\}^{T}[I]\right]\{A(\{S\}, \omega)\}=[V]^{T}\left\{R_{0}\right\}$,

The solution to this system of equations in the following formulas for finding the displacement amplitudes of the forced oscillations is as follows:

\subsection{Methods of model analysis and the purpose of the study}

Model analysis was conducted to determine the scope and general purpose of the types of models in this scientific article. The dependence of the displacement amplitudes of forced oscillations on the frequencies in the transient range is selected as the main characteristic by which the limits are determined. This range is one of the most significant, since it is the process of starting and stopping the power system (turbines and other equipment) that is most likely to fail. The amplitude of the forced oscillations is one of the parameters indicating the efficiency or emergency situation of the system with the turbine.

The comparison of the characteristics of oscillations was conducted qualitatively and quantitatively. Two of them are selected as the baseline characteristics, which are compared with all others: the oscillation characteristics according to the basic model and the experimental data. The basic model corresponds to the general modeling methodology that is common among researchers. The

$\{A(\{S\}, \omega)\}=[V]\left[\operatorname{diag} \frac{e^{i \phi_{j}}}{\sqrt{\left(p_{j}^{2}-\omega^{2}\right)^{2}+4 \omega^{2} p_{j}^{2} n_{j}^{2}}}\right][V]^{T}\left\{R_{0}\right\}, \operatorname{tg} \phi_{j}=\frac{2 \omega p_{j} n_{j}}{p_{j}^{2}-\omega^{2}}$,

where $\{A(\{S\}, \omega)\}$ is the vector of the displacement amplitudes of forced oscillations; [V] is the matrix of system's eigen forms; $p_{j}$ is the $j$-th natural frequency of the system; $n_{j}$ is the damping coefficient of the $j$-th eigenform; $\omega$ is the forced load frequency.

A more detailed description of the solution to the problem of stationary forced oscillations can be found in [38].

For the model with regard to the drawdowns, additional calculations concerning the static contact problem were performed. In it, the connection in the vertical direction is made instead of a rigid system by the contact pseudoelements $\left[C^{K}\right]$. With the help of the constructed finite element model, the following formula is calculated:

$\left[C_{d}+C^{K}\right]\{q\}=\{R\}$

The result of this problem is to determine the deformed state of the turbine, which provides the static position of the turbine for the given realization of the variable vector $\{S\}$ and the contact sites. The calculation likewise makes it possible to find the magnitudes of the gaps in contactless places. convenience of this comparison is the ability to compare the oscillation levels in almost all elements of a power unit system with a turbine. The experimental data provided by the author is meant for a separate dependence of displacement amplitudes of forced oscillations. However, it is experimental data that is the most important criterion for evaluating the results obtained.

The most important elements of the system in terms of oscillations are the system of rotors and their supports. It is the level of oscillations in the supports that most significantly affects the system's performance or the emergency occurrence. Therefore, analysis of oscillations is focused precisely on the characteristics of forced oscillations for the supports of the rotor system in the most flexible elements of the system. For the turbine under consideration, these supports are located in low pressure cylinders. The largest values of the displacement amplitudes of forced oscillations are in the vertical direction. This circumstance is related to the action of gravity. Therefore, the greatest attention is given to the amplitude of oscillations in this direction. Fluctuations in other directions have much smaller values of vertical vibrational displacements. 


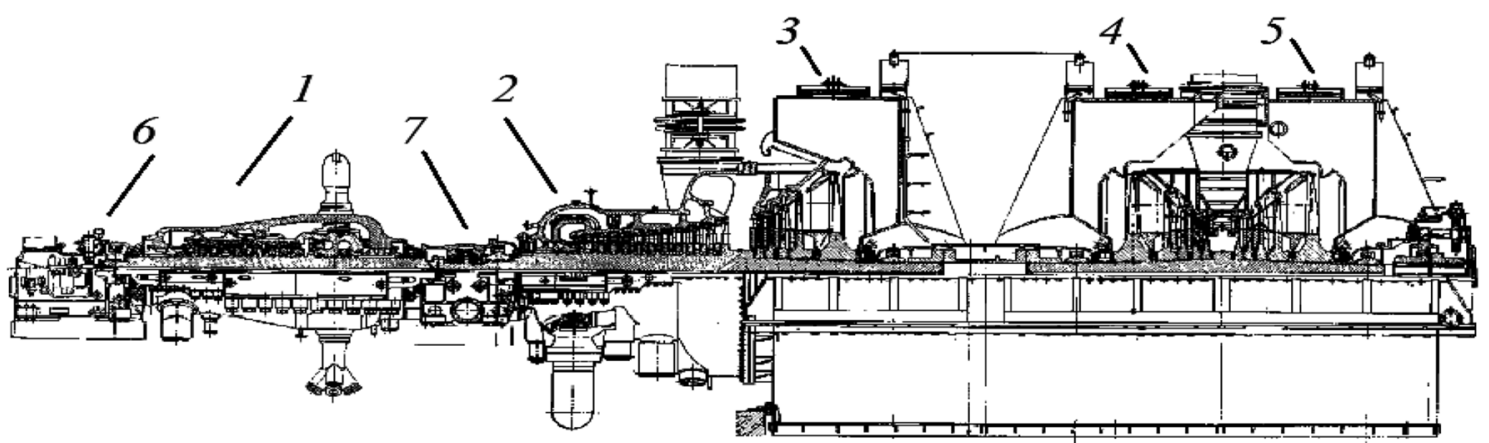

Fig. 1 Steam turbine K-300-240: 1-high pressure cylinder; 2-medium pressure cylinder; 3-5-low pressure cylinders; 6-7-bearing cases 1 and 2

$\Delta=\sum \frac{\left|A_{j}-A_{j E}\right|}{A_{j E}} * 100 \%$

The adequacy of the models is assessed according to formula (20). The average relative error $\Delta$ is used to perform this verification. In formula (20): $A_{j}$ is the amplitude of forced oscillations checked by the model at the $j$ frequency, $A_{j E}$ is the amplitude of the forced oscillations from the experiment at the $j$ frequency. To assess the adequacy of the models, the range of transients is $30-45 \mathrm{~Hz}$. Experimental values were obtained by vibration diagnostics when stopping the turbine unit for scheduled maintenance and repair. Below the frequency of $30 \mathrm{~Hz}$ is the first resonance, so the retrieval of experimental data in the low frequency range was not possible. This is due to the need for this violation of the rules of the thermal power plant operation and, as a consequence, the possibility of an emergency.

\section{Types of 3D models and their construction}

\subsection{Relationship between models}

The models were designed for a power unit with a K-300240 condensation steam turbine (Fig. 1). It is one of the most widely used steam turbines in the world-more than hundred units are manufactured and operated. All the developed models have part of the basic model. The basic model consists of the following parts: turbine, foundation, base (soil and other), generator and other parts of the system. First, models of individual parts of the system were developed and then a basic model (model 10) was built from them. The simplified model is a model based solely on the turbine (model 9) included in the base model. Other models are derived from the basic model 10. The most complex is the variable contact model (model 16).
It is derived from a model with rigid contact (model 15), which in turn is derived from a model with subsidence (model 14). And the model 14 is derived directly from the basic model 10.

The physical model of the system consists of 4 main elements: a foundation is installed on the ground, on which a steam turbine (Fig. 1) and a generator are installed. A steam turbine typically consists of three cylinder types: low pressure, medium pressure and high pressure. Bearing cases 3-5 are built into the corresponding low pressure cylinders 1-3 (positions 3-5 in Fig. 1). In all models, the high pressure cylinder of the turbine was modeled using a mass system. Other parts of the system using spatial models with using of shell and beam types of finite elements. The system of rotors with disks and blades was taken into account through the mass system. This is to focus on the vibrations of the rotor supports, not the rotors themselves.

\subsection{Basic model and mathematical validation}

The basic model consists of three-dimensional foundation models and two types of turbine cylinders models. The base is taken into account by the tight connections at the ends of the foundation on the side of the floor. Capacitors are also taken into account by the connection system. Generator, high pressure cylinder, rotors are taken into account by means of mass system.

The connection of the three-dimensional models of the turbine and the foundation is made by the rigidity system. Vertical rigidities are selected according to full rigid contact, horizontal ones have elastic effect. The points of fixation of the turbine on the foundation are taken into account. The basic model is shown in Fig. 2 (geometric model) and Fig. 3 (computational model 10).

In Fig. 4 shows half of the computational model 11, which has an increased degree of sampling. In Fig. 5 shows the load locations. The force P1 is applied to support No. 3 . 
Fig. 2 Geometric basic model

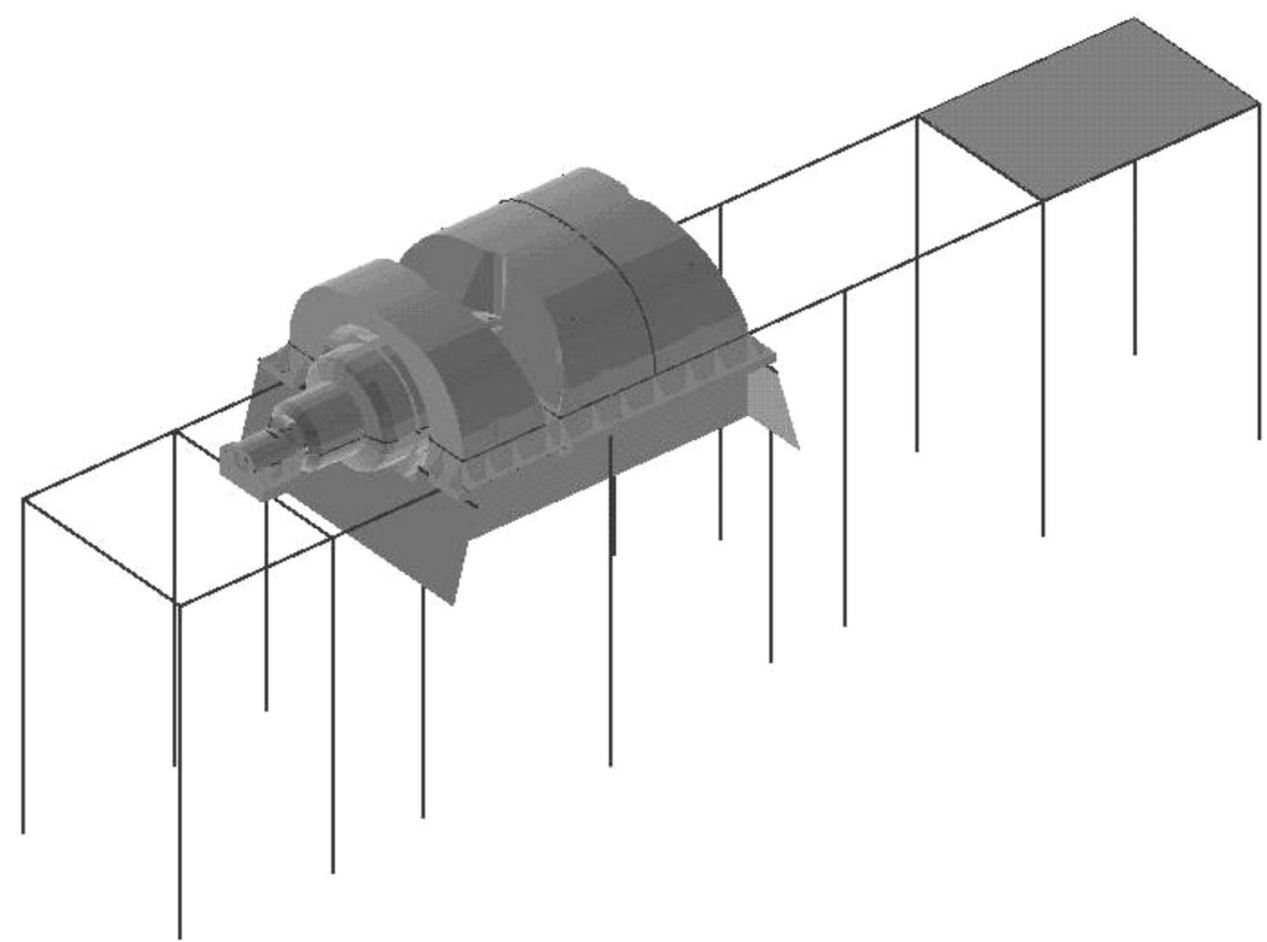

Fig. 3 Computational basic model 10 with a low degree of sampling

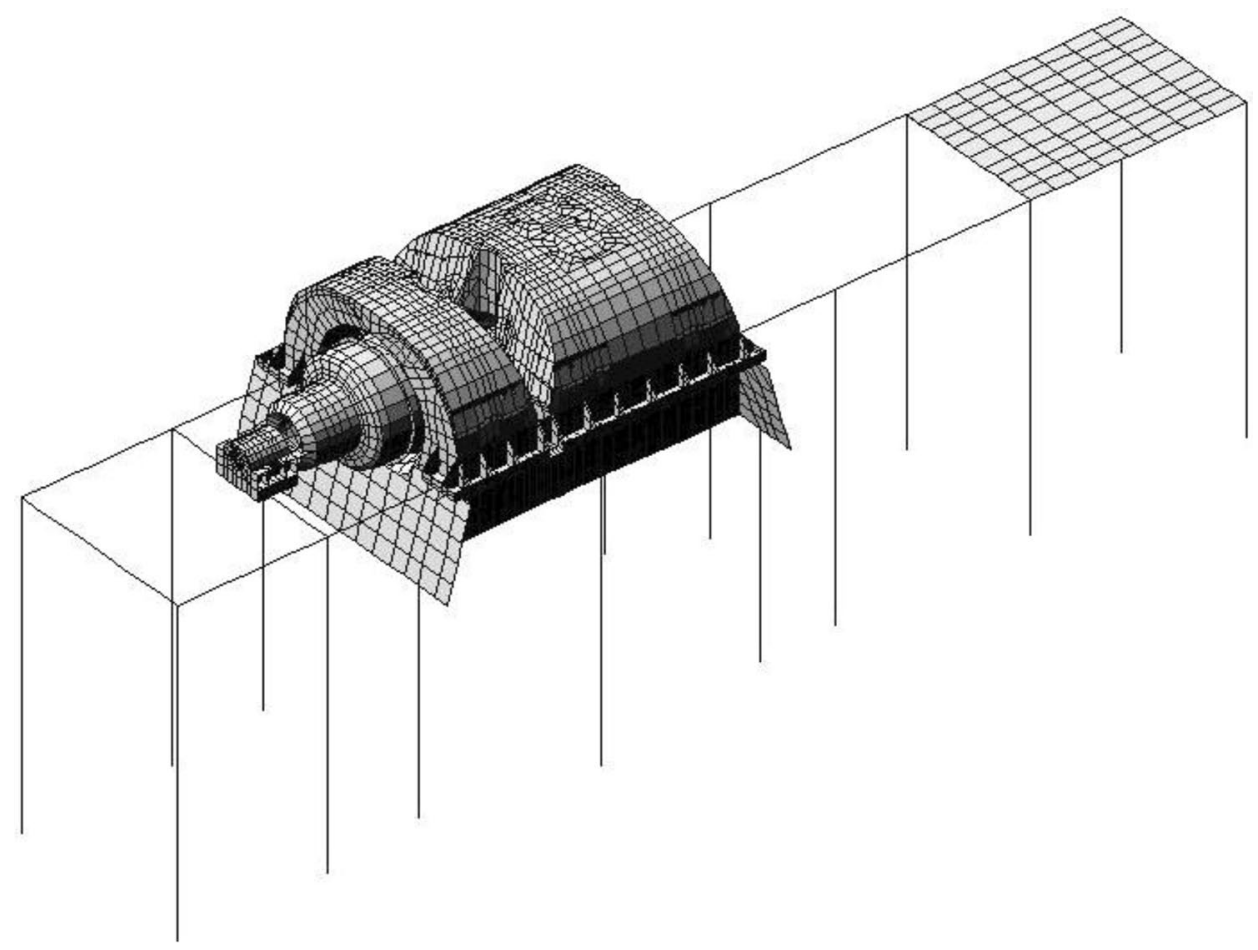

The forces P2 are applied according to supports No. 4 and P3 are applied according to supports No. 5. The forces were one load at a time. The displacement amplitudes of the oscillations of the supports at each calculation were taken to study at the points of application of the forced load.
Damping was taken by atomic, the standard modal model for its consideration. The value of each force is $1 \mathrm{~N}$. Table 1 shows the model parameters. The comparison of the amplitude dependences of the forced oscillations on the frequencies for models 10 and 11 (model 11 has a greater 
Fig. 4 Computational basic model 11 with a high degree of sampling

Fig. 5 Computational simplified model 9 with a low degree of sampling

Table 1 Parameters of the computational models
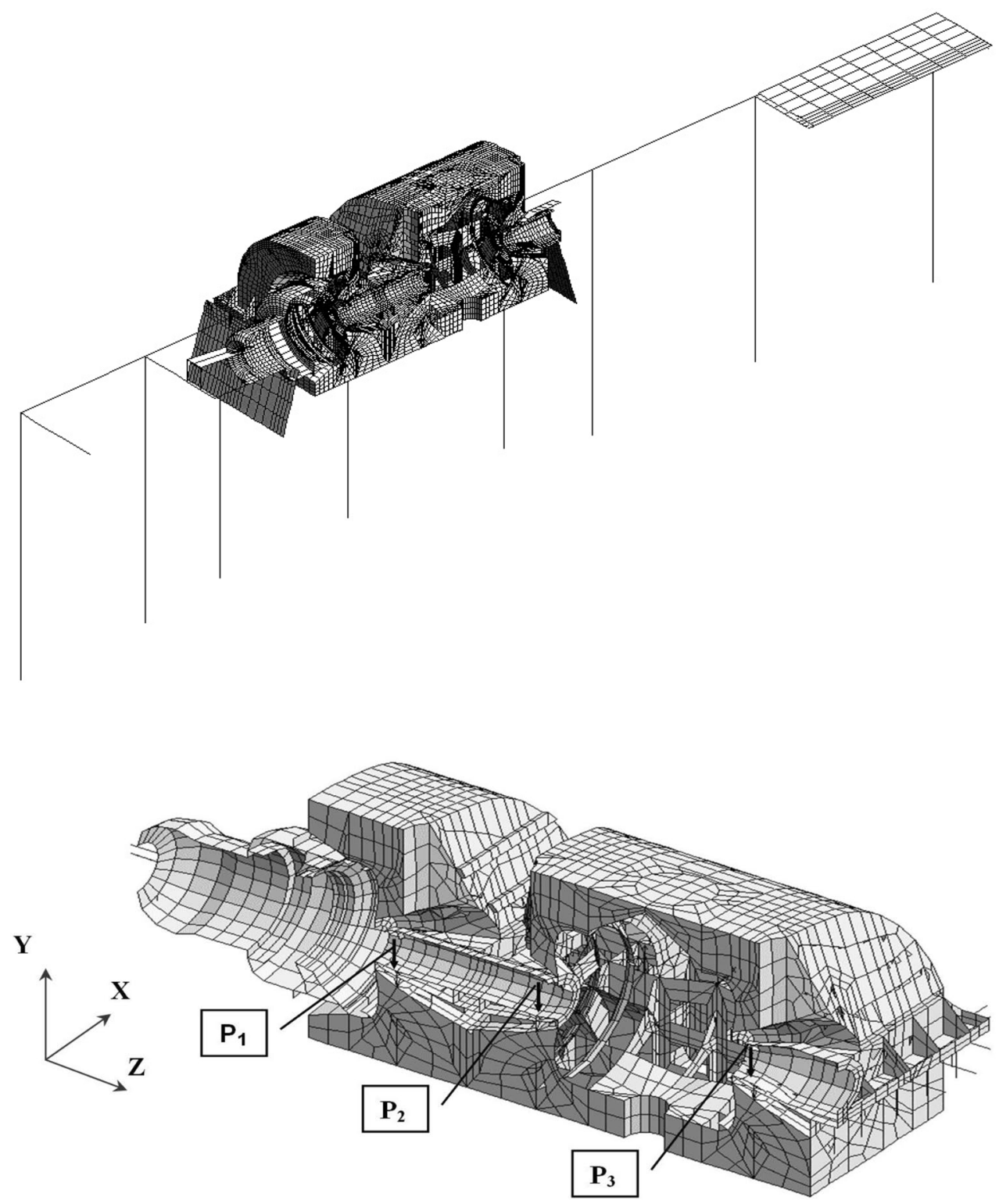

Model Description of models No

Figure Number

Degrees of Elements Nodes

freedom

\begin{tabular}{llrrrr}
\hline 10 & Basic 1 & 3 & 90,422 & 17,694 & 15,150 \\
11 & Basic 2 & 4 & 152,430 & 31,604 & 27,520 \\
9 & Simplified & 5 & 76,584 & 15,628 & 13,508 \\
12 & taking into account the rigidity of the soil & 8 & 91,002 & 18,426 & 16,044 \\
13 & taking into account the rigidity of the generator & 10 & 93,938 & 19,028 & 16,988 \\
14 & taking into account the drawdowns & 3 & 90,422 & 17,694 & 15,150 \\
15 & taking into account hard contact & 3 & 90,542 & 17,624 & 15,150 \\
16 & taking into account variable contact & 3 & 90,422 & 17,694 & 15,150 \\
\hline
\end{tabular}


number of degrees of freedom) showed that the qualitative indicators of the dependences coincide completely (Fig. 11). Quantitative indicators according to the results of calculations on the maximum values of the displacement amplitudes in the transient stage have a maximum value of the absolute error of $510^{-11} \mathrm{~m}$, which is $9.3 \%$.

The connection of the three-dimensional models of the turbine and the foundation is made by the rigidity system. Vertical rigidities are selected according to full rigid contact, horizontal ones have elastic effect. The points of fixation of the turbine on the foundation are taken into account. The basic model is shown in Fig. 2 (geometric model) and Fig. 3 (computational model 10).

In Fig. 4 shows half of the computational model 11, which has an increased degree of sampling. In Fig. 5 shows the load locations. The force P1 is applied to support No. 3. The forces $\mathrm{P} 2$ are applied according to supports No. 4 and P3 are applied according to supports No. 5. The forces were one load at a time. The displacement amplitudes of the oscillations of the supports at each calculation were taken to study at the points of application of the forced load. Damping was taken by atomic, the standard modal model for its consideration. The value of each force is $1 \mathrm{~N}$. Table 1 shows the model parameters. The comparison of the amplitude dependences of the forced oscillations on the frequencies for models 10 and 11 (model 11 has a greater number of degrees of freedom) showed that the qualitative indicators of the dependences coincide completely (Fig. 11). Quantitative indicators according to the results of calculations on the maximum values of the displacement amplitudes in the transient stage have a maximum value of the absolute error of $510^{-11} \mathrm{~m}$, which is $9.3 \%$.

Thus, the calculation error between models 10 and 11 is less than $10 \%$. The minimum value of error in the calculations is $0 \mathrm{~m}$ and $0 \%$. The average value of the error at the

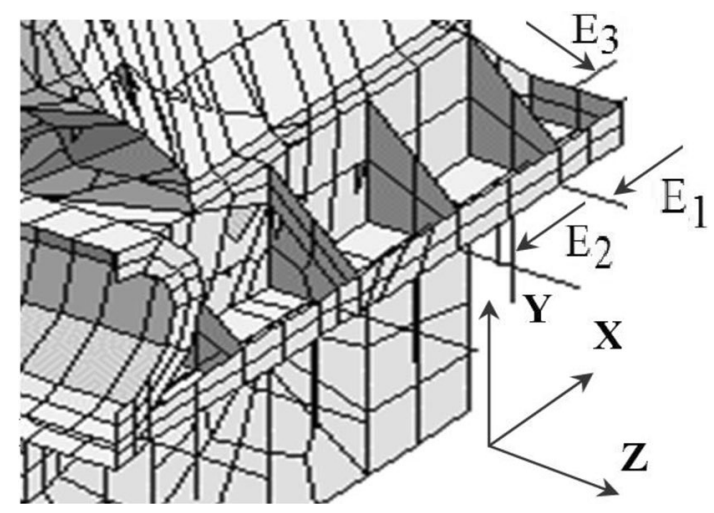

Fig. 7 The foundation system that models the foundation in a simplified calculation model 9

transitional stage: absolute is $1.210^{-11} \mathrm{~m}$, relative is $5 \%$. Therefore, for further calculations and modeling, the sample rate corresponding to model 10 is taken as the basis.

\subsection{Simplified model}

The simplified model consists only of a three-dimensional model of two types of turbine cylinders. The model 9 is shown in Fig. 5. The geometric model is shown in Fig. 6. The foundation is taken into account by means of a system of rods, which is shown in Fig. 7. In places where the turbine is touching the foundation there is a system of three rigidities (E1, E2, E3) in each spatial direction ( $X, Y$, $Z$ ). The rigidity in the vertical direction (E2) is much greater than the rigidity in the horizontal direction (E1 and E3). The rotors are taken into account by the mass system. The capacitors are taken into account by the communication system. Other parts of the power unit (generator, highpressure cylinder) in the calculation model 9 are missing.

Fig. 6 Geometric simplified model 9

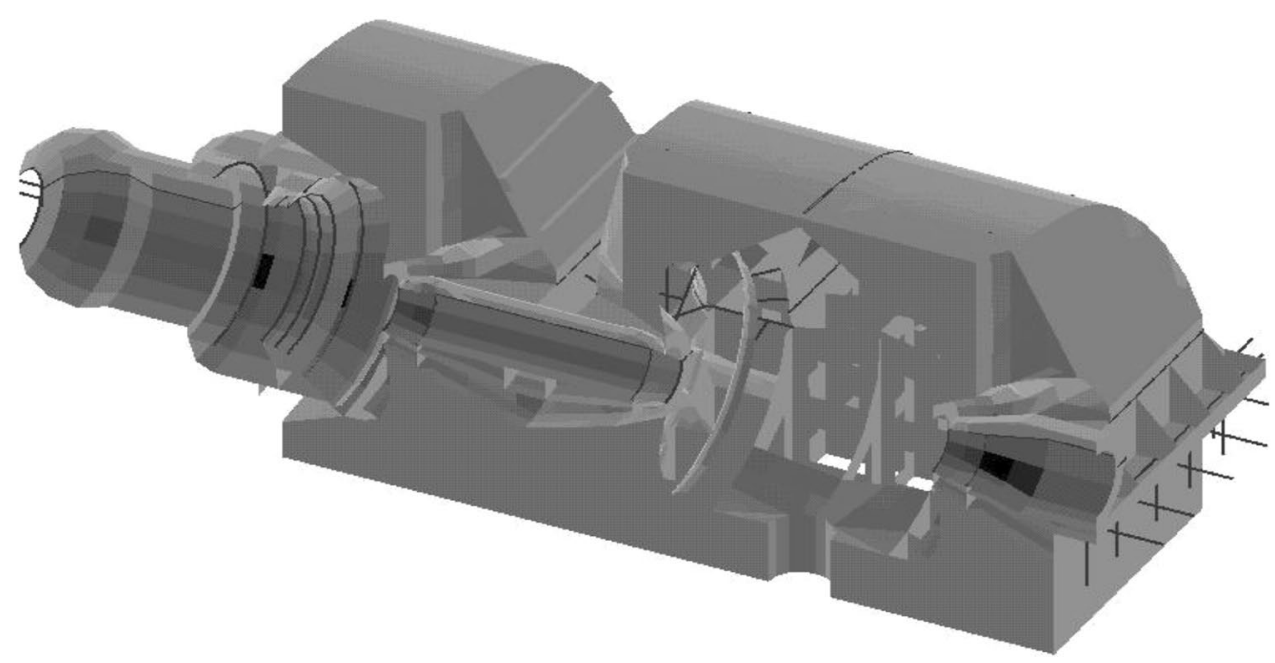




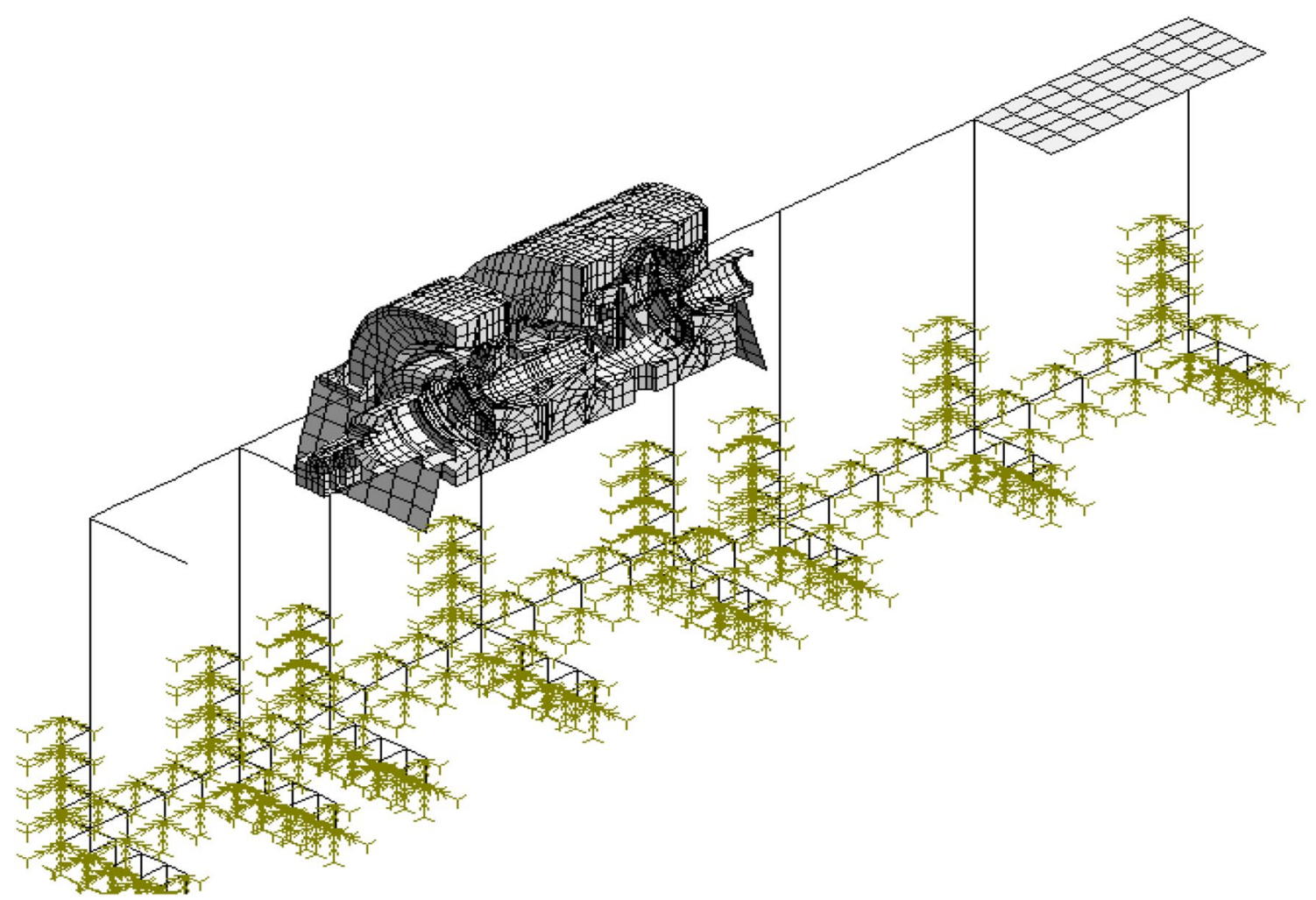

Fig. 8 Model 11, taking into account the rigidity of the soil

Fig. 9 Geometric model with generator

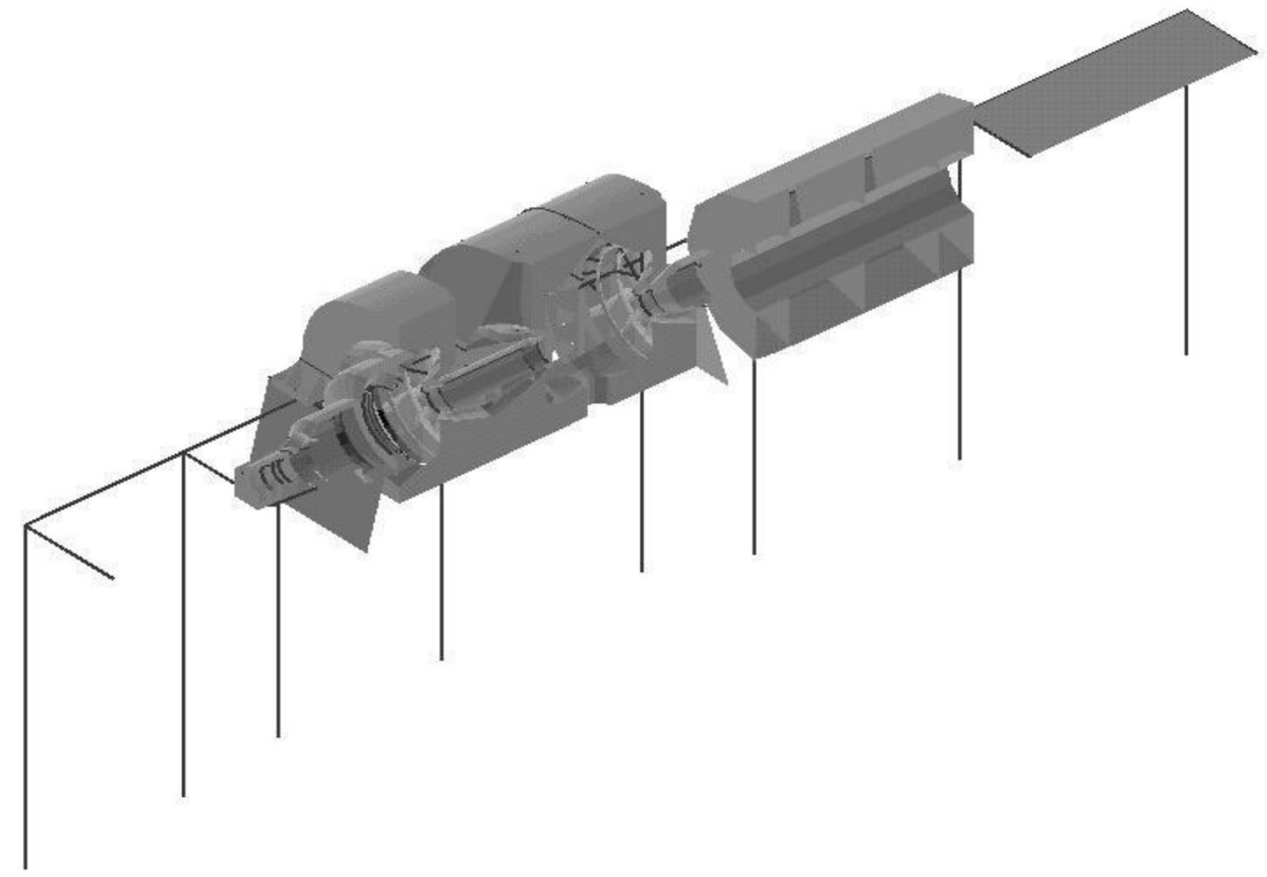

\subsection{Consideration of soil stiffness}

The soil stiffness model differs from the basic soil stiffener modeled by Winkler. The model 12 is shown in Fig. 8 . The rigidity system is applied to the part of the foundation, which is completely filled with soil and concrete floor. Part of the foundation above the soil has no additional rigidity. 
Fig. 10 Model 12, taking into account the stiffness of the generator

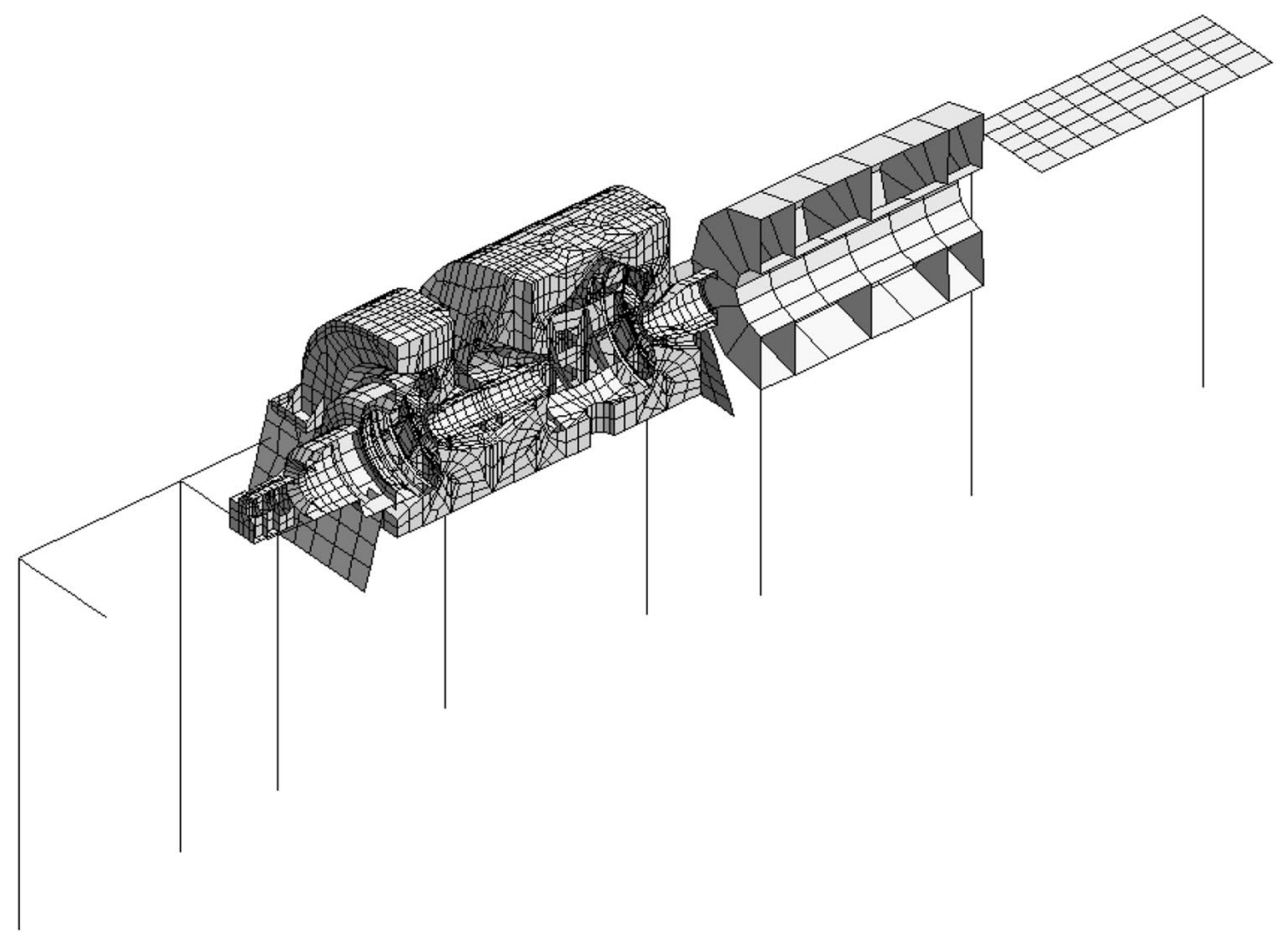

\subsection{Consideration of generator stiffness}

To account for the stiffness of the generator, its threedimensional model was built, which was added to the basic calculation model 10. In Fig. 9 shows a geometric model. Figure 10 shows the design model 13 . The generator model was built using shell and core elements. The rotor of the generator is taken into account by the mass system.

\subsection{Consideration of the subsidence of the foundation}

Due to the technological features and operating conditions, each foundation of the power unit has a drawdown of its columns. Depending on the type of soil, the type of foundation, the conditions of construction and operation

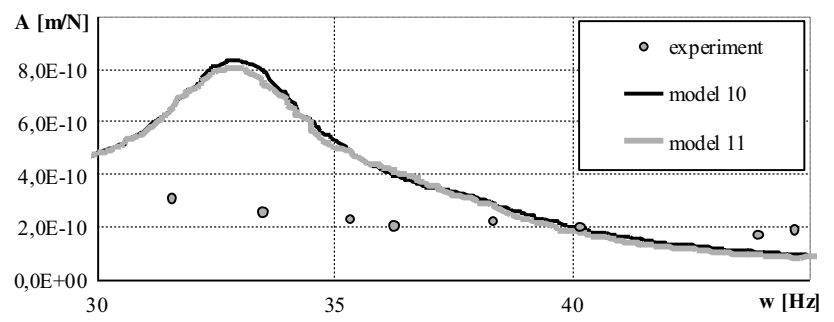

Fig. 11 Dependences of the displacement amplitudes of the forced oscillations of the support No. 4 on the frequencies for models 10 (basic) and 11 (basic with a high degree of sampling) of the sizes of subsidence have different meanings. The maximum fixed values of the subsidence of the columns of the foundation are more than $100 \mathrm{~mm}$. Due to the fact that all foundations for K-300-240 turbines have a lifetime of more than 30 years, most of the drawdowns are large. Visually, the appearance of the design model with drawings (model 14) does not differ from that shown in Fig. 3. However, this model takes into account the deformation of the foundation and the turbine under the influence of weight. The connection between the base and the turbine is the same as that found in the base model.

\subsection{Considering hard contact}

The rigid contact design model (model 15) is derived from model 14. Its appearance also does not differ from that shown in Fig. 3. The peculiarity of this model is to model the connections between the foundation and the turbine. The fact is that the low-pressure cylinders of the K-300-240 turbine lie freely on the foundation. In fact, the base turbine is coupled with the help of weight forces. However, the turbine is in a vibrating state during operation. Therefore, two states (constant and alternating contact) and three states (full contact, alternating interaction, free state) can be distinguished from the contact states of the turbine with the foundation. Model 15 takes into account two boundary states: full contact and free state. For its construction the solution of the contact problem is performed. According to its results, specific places were obtained where the contact of the base with the turbine 


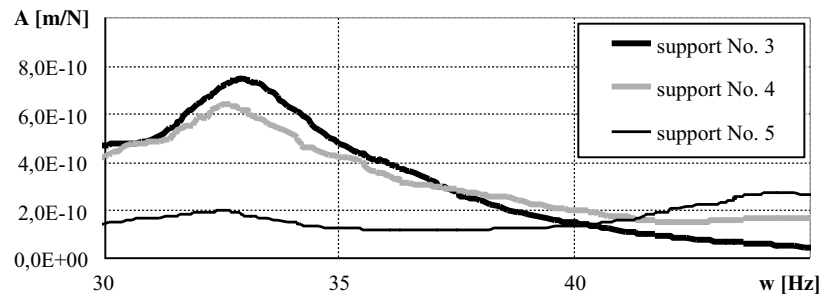

Fig. 12 Dependence of the displacement amplitudes of the forced oscillations of the supports No. 3, 4, 5 on the frequencies for the model 10 (basic with a low degree of sampling)

was complete. In these places there is a strong connection between the foundation and the turbine. Elsewhere, there is no connection between the foundation and the turbine.

\subsection{Consideration of alternating contact}

The most complex model for the construction of the variable contact between the foundation and the turbine (model 16) is derived from model 15. For its construction, in addition to the calculations of static gravity and contact problems, the dynamics problem for obtaining the displacement amplitudes of forced oscillations on model 15 was performed. Displacement amplitudes of oscillations of the turbine at its points of contact with the base are obtained. These values were compared with the values of the gaps between the turbine and the foundation according to the calculation of the contact problem. With these two solutions, the stiffness of contact interaction $\left[C^{K}\right]$ (formula 19) was obtained. The components $\left[C^{K}\right]$ are three rigidity vectors in each coordinate direction, from which rigidity E1, E2, E3 are selected for the contact point, as shown in Fig. 7. In places of full contact, the rigid connection between the turbine and the base is left. Elsewhere, this contact is not hard. Thus, in model 16, the coupling between the turbine and the base is variable and takes into account all three states of interaction: full contact, variable interaction, free state.

\section{Analysis of forced oscillations}

\subsection{Models without foundation subsidence}

In Fig. 11 shows the dependencies of the amplitude of the forced oscillations on the frequencies for the models 10 and 11. In addition, the points with experimental data are also shown. From Fig. 11 we see that these calculations almost coincide. However, the experimental data are significantly different qualitatively and quantitatively with the calculation data for models 10 and 11 .
In Fig. 12 show the dependences of the amplitude of the forced oscillations on the frequencies for the rotor supports No. 3, 4, 5 for model 10 . We see that for the rotor supports.

No. 3 and 4, the dependences have a quantitative difference, but the same qualitative character with one pronounced system resonance. The dependence for the rotor support No. 5 differs from the dependencies for the support No. 3 and No. 4 quantitatively and qualitatively, and also has two significant resonances of the system.

In Fig. 13 show the dependences of the characteristics of the forced oscillations for the supports of rotors No. 3 , 4,5 for model 9 . We see that for the supports of rotors No. 3 and 4 , the dependencies also have the same features as for model 10: there is a quantitative difference, however same quality character with one pronounced resonance of the system. It should be noted that the resonance in model 10 is up to $35 \mathrm{~Hz}$, in model 9 is after $35 \mathrm{~Hz}$. The dependence for the rotor support No. 5 also to the model 10 differs from the dependences for the supports No. 3 and No. 4 quantitatively and qualitatively, and also has two significant resonances of the system.

In Fig. 14 shows the dependences of the amplitude of the forced oscillations on the frequencies for the rotor supports No. 4 for models 10 and 12. From Fig. 14 we see that the results for model 12 are almost no qualitatively and quantitatively different from the results for model 10. However, they have a significant difference with the experimental data.

In Fig. 15 shows the dependences of the characteristics of the forced oscillations for the rotor supports No. 4 for models 10 and 13. From Fig. 15 also shows in the previous case that the results for model 13 are almost indistinguishable qualitatively and quantitatively from the results for model 10. However, they also differ significantly from the experimental data on the displacement amplitudes of oscillations.

The aforementioned indicates that the rigidity of the soil, the generator and the simplicity of the models are not sufficiently taken into account to ensure the reliability of the results obtained. Therefore, a series of models with subsidence were developed, the results of which are given below.

\subsection{Models taking into account subsidence of foundation columns}

In Figs. 16, 17 show the results of the calculations of the displacement amplitudes of the forced oscillations for the rotor supports No. 4 for models 14, 15, and 16. From Fig. 16 we see that already the first model with regard to 


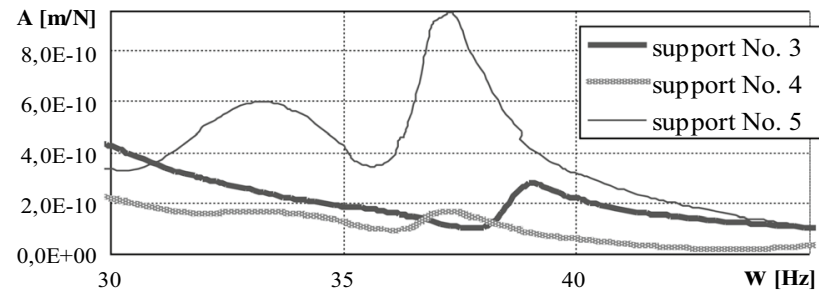

Fig. 13 Dependences of the displacement amplitudes of the forced oscillations of the supports No. 3, 4, 5 on the frequencies for the model 9 (simplified with a low degree of sampling)

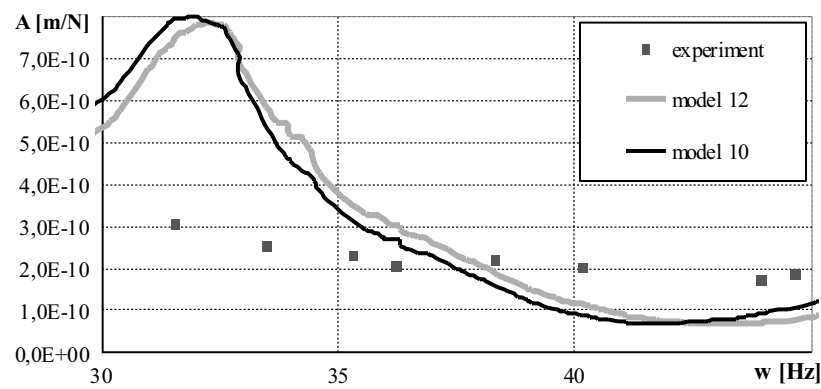

Fig. 14 Dependence of the displacement amplitudes of the forced oscillations of the support No. 4 on the frequencies for models 10 (basic) and 12 (taking into account the rigidity of the soil)

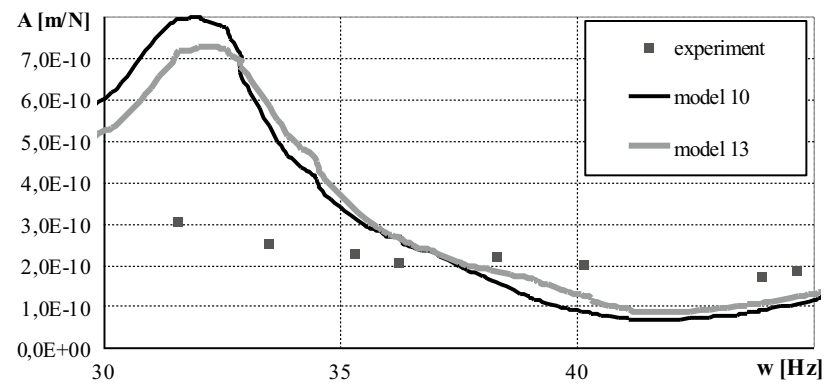

Fig. 15 Amplitude dependences of the forced oscillations of the support No. 4 on the frequencies for models 10 (basic) and 13 (taking into account the rigidity of the generator)

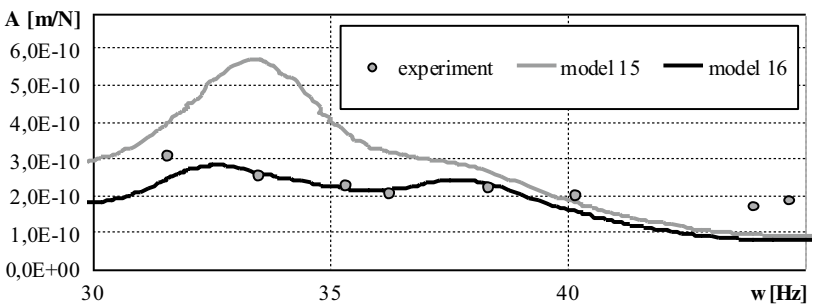

Fig. 17 Dependences of the displacement amplitudes of the forced oscillations of the support No. 4 on the frequencies for models 15 (hard contact) and 16 (variable contact)

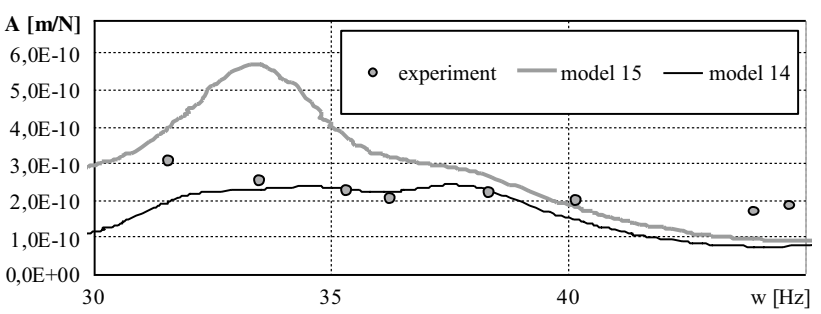

Fig. 16 Dependence of the displacement amplitudes of the forced oscillations of the support No. 4 on the frequencies for models 14 (taking into account the drawdowns) and 15 (taking into account hard contact)

the subsidence of the foundation (model 14) at the transitional stage significantly approximates the results of the calculations to the experimental ones. The dependences of the characteristics of the forced oscillations are almost indistinguishable from the experimental ones in qualitative form and quantitative values in the range of $33-43 \mathrm{~Hz}$ (Fig. 16). The highest qualitative and quantitative differences are in the range up to $44,5 \mathrm{~Hz}$. It is $59 \%$. The smallest deviation of $2-10 \%$ in the range of $33-43 \mathrm{~Hz}$.

Further development of models for specifying the operating conditions of a $300 \mathrm{MW}$ steam turbine power unit leads to the emergence of model 15. It takes into account two limiting states of the resistance of the turbine to the foundation: rigid and free. From Fig. 16 we can see that model 15 provides results that are significantly different

Table 2 Numerical assessment of the adequacy of models

\begin{tabular}{|c|c|c|c|c|c|}
\hline \multirow{2}{*}{$\begin{array}{l}\text { Model } \\
\text { No }\end{array}$} & \multirow[t]{2}{*}{ Description of models } & \multirow[t]{2}{*}{ Figure } & \multicolumn{3}{|c|}{ Relative error, \% } \\
\hline & & & maximum & minimum & average $(\Delta)$ \\
\hline 10 & Basic & $11,14,15$ & 212 & 0 & 8 \\
\hline 11 & Basic & 11 & 193 & 8 & 8 \\
\hline 12 & taking into account the rigidity of the soil & 14 & 148 & 11 & 8 \\
\hline 13 & taking into account the rigidity of the generator & 15 & 134 & 10 & 6 \\
\hline 14 & taking into account the drawdowns & 16 & 59 & 2 & 3 \\
\hline 15 & taking into account hard contact & 16,17 & 124 & 7 & 4 \\
\hline 16 & taking into account variable contact & 17 & 59 & 1 & 2 \\
\hline
\end{tabular}


from the experimental ones. The largest error is $124 \%$ ( $35 \mathrm{~Hz})$, the smallest is $7 \%(40 \mathrm{~Hz})$.

Model 16 takes into account the three states of resistance of the turbine to the foundation: rigid, free and variable. From Fig. 17 we see that this model allows us to obtain results from the calculation of the characteristics of the forced oscillations, which are closest to the experimental ones. The largest error is 59\% (at frequencies exceeding $44,5 \mathrm{~Hz}$ ), the smallest error is $1-11 \%$ (most long range 33-43 Hz). Thus, models 14 and 16 provide the results of the computations of the displacement amplitudes of the forced oscillations in the range $33-43 \mathrm{~Hz}$ with high accuracy.

Table 2 shows the results of the numerical assessment of the adequacy of the models. From this table it is clear that the model taking into account the variable contact (model 16) is the most likely of the models considered in this study. The study shows that to build reliable models of rotor systems it is necessary to take into account the subsidence of the foundation and the variable contact between the stator elements.

\section{Discussion (Directions for increasing the accuracy of results and the realism of models)}

It should be noted that each real problem has many features and directions for optimization. Here are only two possible directions. The first concerns the most simplified model 9, and the second for the most complex model 16.

So model 9, which is considered unsuitable for calculations, can be improved by specifying the data on the stiffness of the foundation at all places of resistance of the turbine to the foundation. Of course, this information will allow you to use model 9 and obtain results that must be reliable (have the smallest difference with the experimental data). However, further experimental or computational studies are required to obtain this data. This raises the question of the feasibility of these works and the advantages of the model 9 over the model 16 . Of course, these advantages are in terms of size and complexity of the model. However, model 16 allows reliable results to be obtained without further research on specialized inputs.

Also note that the capabilities of the model 16 are not fully disclosed. The fact is that the overall average characteristics of the contact interaction of the turbine with the foundation were used to build the existing model. Of course, at different frequencies, this dynamic interaction is different. Therefore, the model 16 has additional directions to optimize and improve the reliability of the results obtained from it calculations on vibration characteristics.
The modern model of a real machine-building structure (for example, a turbine unit) is a complex system. Depending on the type of subsequent analysis, any structure is modeled with simplifications. Any calculation has its own simplifications associated with the limitations of the theory used. The author considers, that the choice of theory and research methods is the choice of each specialist. But every specialist should know the factors influencing the research results and the degree of their influence. The author has completed a large amount of tasks (development of methods, modeling, calculations, analysis) to analyze the problem. This article examines several factors and analyzes their influence on the results of calculations of forced stationary vibrations of a complex mechanical system. Which factors should be considered and which should not be chosen take into account should be chosen by the researcher. The materials for this choice are provided by the author in this article.

\section{Conclusions}

The investigation series with models of power unit with K-300-240 turbine shows the inapplicability of common modeling methods for stator parts for systems with rotor and flexible contact between rotor and stator parts. Taking into account the influence of soil and all flexible stator systems does not significantly improve the results of the computations of the displacement amplitudes of the forced oscillations. It is shown that taking into account the subsidence of the foundation and the dynamic interaction of the stator (medium and low pressure turbine housings) with the foundation make it possible to obtain results with high accuracy and realism. Models developed using the general three-dimensional simulation technique can be used as a rapid sensitivity analysis to change system parameters or as reliable after additional experimental or computational studies to obtain the necessary input data. The result of the work was used in the design and optimization of upgrades of the K-300-240 turbine. To improve the accuracy of the results of calculations of forced vibrations for rotor systems with a variable contact zone between the stator and the rotor, it is necessary to take into account the change in the position of static equilibrium and the features of the variable contact zone (model 16). Other factors considered in the work have a much smaller effect on the displacement amplitudes of forced vibrations of the rotor supports.

Authors' contributions All works are performed personally by the author. 
Funding The work was carried out without funding.

Data availability For experts in the field of this study, data is open.

\section{Declarations}

Conflict of interest On behalf of author, the corresponding author states that there is no conflict of interest.

Code availability New special program code was not used during research work.

Open Access This article is licensed under a Creative Commons Attribution 4.0 International License, which permits use, sharing, adaptation, distribution and reproduction in any medium or format, as long as you give appropriate credit to the original author(s) and the source, provide a link to the Creative Commons licence, and indicate if changes were made. The images or other third party material in this article are included in the article's Creative Commons licence, unless indicated otherwise in a credit line to the material. If material is not included in the article's Creative Commons licence and your intended use is not permitted by statutory regulation or exceeds the permitted use, you will need to obtain permission directly from the copyright holder. To view a copy of this licence, visit http://creativecommons. org/licenses/by/4.0/.

\section{References}

1. Herz F., Nordmann R. (2020). Vibrations of Power Plant Machines. Springer. 266

2. Hiroshi Kank, Masao Kobayashi, Masato Tanaka, Osami Matsushita, Patrick Keogh (2019). Vibrations of Rotating Machinery. Volume 2. Advanced Rotordynamics: Applications of Analysis, Troubleshooting and Diagnosis. Springer

3. Chernousenko O.Y., Peshko V.A., Rindyuk D.V. (2019). Analysis of the opportunity to extend the operation of the intermediate pressure rotor with critical size cracks. Visnik NTU "KhPl", 1:4-9

4. Garmash NG, Gontarovskiy PP, Melezhik II, Shulzhenko NG (2018) Design forecasting of thermal strength and resource of steam turbine structural components. Problems of mashinebuilding 21(3):38-46

5. Van Thanh Ngo (2016) Comparison behavior of a large turbo machine vibration between unbalance and bent shaft. Vietnam J Sci Technol. https://doi.org/10.15625/0866-708X/54/2/6164

6. Avramov K, Malyshev S (2019) Bifurcations and chaotic forced vibrations of cantilever beams with breathing cracks. Eng Fract Mech 214:289-303

7. Avramov K, Nikonov O, Uspensky B (2019) Nonlinear modes of piecewise linear systems forced vibrations close to superharmonic resonances. Proc Inst Mech Eng 233(23-24):7489-7497

8. Baginski P, Banaszek S, Zywica G (2016) Experimental studies on foil bearing with a sliding coating made of synthetic material. J Tribol 138(1):1-10. https://doi.org/10.1115/1.4031396

9. Dengqing C, Guo C, Huajiang O, Yang Y, Yiren Y (2020) Nonlinear vibration mitigation of a rotor-casing system subjected to imbalance-looseness-rub coupled fault. Int J Non-Linear Mechan 122:103467

10. Khairul J (2018) Vibration reduction of spindle-bearing system by design optimization. WSEAS Trans Appl Theor Mech 13:85-91

11. Cao D, Ouyang $H$, Wang $K$, Yang $Y$, Yiren $Y(2020)$ Vibration analysis of a dual-rotor-bearing-double casing system with pedestal looseness and multi-stage turbine blade-casing rub. Mech Syst
Signal Process 143:106845. https://doi.org/10.1016/j.ymssp. 2020.106845

12. Huang B, Mo JL, Ouyang H, Wang RL, Wang XC (2020) Frictioninduced stick-slip vibration and its experimental validation. Mechanic Syst Signal Process 142:106705

13. Saruhan H, Yucel E (2017) Design optimization of rotor-bearing system considering critical speed using Taguchi method. Proc Inst Mech Eng, Part E: J Process Mech Eng 231(2):138-146

14. Avramov K, Chernobryvko M (2016) Natural vibrations of parabolic shells. J Math Sci 51(4):939-950

15. Avramov KV, Malyshev SE (2018) Periodic, quasi-periodic, and chaotic geometrically nonlinear forced vibrations of a shallow cantilever shell. Acta Mech 229(4):1579-1595

16. Bhattacharya S., Ramanjaneyulu K., Rao A. (2019) Analysis and Design of Tabletop Foundation for Turbine Generators. Recent Advances in Structural Engineering, Volume 1. Lecture Notes in Civil Engineering, vol 11. Springer, Singapore https://doi.org/10. 1007/978-981-13-0362-3_1

17. Garmash N.G., Gontarovskiy P.P., Shulzhenko N.G. (2016). Methodology of calculation of the dynamics of the system turbinefoundation-base power units under seismic actions, Bulletin of "KhPl", 8: 153-160

18. Garmash N., Glyadya A., Gontarovskiy P., Shulzhenko N. (2017). Estimating the Vibrations of Turbounit-Foundation-Base System Exposed to Seismic Loads. Bulletin of NTU "KhPI", 10(1232): 25-29

19. Chen Jianguo Fu, Huairen XZ (2018) Zero output technology of the low-pressure cylinder of $300 \mathrm{MW}$ unit turbine. Thermal Power Generation 47:106-110

20. Danmei Xie, Hengliang Zhang, Huabing Zheng, Xiangjun Huang, Yanan Guo, Ziyue Mei (2018). Numerical Study on Deformation of Gland Seal Housing at LP Ends on a Nuclear Steam Turbine. ASME Turbo Expo 2018: Turbomachinery Technical Conference and Exposition, pp 1-10. https://doi.org/10.1115/GT2018-76277

21. Garmash NG, Grishin NN, Gontarovskii PP, Shul'zhenko N.G. (2015) Torsional vibrations and damageability of turboset shaftings under extraordinary generator loading. Strength Mater 47(2):227-234

22. Gu Weiwei Yu, Xiaobing ZY (2018) Dynamic strength analysis of the low pressure last stage blade under zero-output heating conditions of low pressure cylinder in a power plant. Thermal Power Generation 47(5):63-70

23. Hu C., Wang P., Youn B.D. (2019) Case Studies: Prognostics and Health Management (PHM). In: Engineering Design under Uncertainty and Health Prognostics. Springer Series in Reliability Engineering. Springer, Cham. https://doi.org/10.1007/ 978-3-319-92574-5_9

24. Shicheng $\mathrm{H}$, Li Ying Qu, Dalei, (2018) Research and apply on zero output operation of low pressure cylinder of $350 \mathrm{MW}$ steam turbine. Shandong Electric Power 45:63-67

25. Khadersab A, Shivakumar S (2018) Vibration analysis techniques for rotating machinery and its effect on bearing faults. Procedia Manuf 20:247-252

26. Fazal M, Mehdi SN, Praveen KB (2019) Performance optimization of $500 \mathrm{MW}$ steam turbine by condition monitoring technique using vibration analysis method. Int J Adv Res Eng Technol 10(5):1-8. https://doi.org/10.34218/IJARET.10.5.2019.001

27. Dong D, Hua C, Ouyang H, Zhao W (2019) A novel method for identifying crack and shaft misalignment faults in rotor systems under noisy environments based on CNN. Sensors 19(23):5158. https://doi.org/10.3390/s19235158

28. Dou D, Zhou Z (2016) Comparison of four direct classification methods for intelligent fault diagnosis of rotating machinery. Appl Soft Comput 46:459-468

29. Fuan W, Haidong S, Hongkai J, Huiwei Z (2017) A novel deep autoencoder feature learning method for rotating machinery fault diagnosis. Mech Syst Signal Process 95:187-204 
30. Ganesh R. Sankar, Iqbal Muhammad Zeeshan (2016). Case study on remote diagnostics in resolving random vibration on a steam turbine. Turbomachinery Laboratories, Texas A\&M Engineering Experiment Station. https://doi.org/10.21423/R1C68S. http:// hdl.handle.net/1969.1/160249. Accessed 24 August 2020

31. Avramov KV, Martynenko GY, Martynenko VG, Rusanov AV, Varlahov VO (2017) Determination of rupture sources of turbine blade packets at performance of forensic examinations. Theor Practice Forensic Sci Criminalistics 17:297-307

32. Avramov K., Martynenko G., Martynenko V., Rusanov A. (2018). Detection of accident causes on turbine-generator sets by means of numerical simulations. IEEE 3rd International Conference on Intelligent Energy and Power Systems (IEPS), pp 51-54

33. Choi W, Kim NH, Oh H, Youn BD (2019) A Bayesian approach for a damage growth model using sporadically measured and heterogeneous on-site data from a steam turbine. Reliab Eng Syst Saf 184:137-150

34. Kendzera OV (2015) Seismic hazard assessment and protection against earthquakes. Herald Academy Sci 2:44-57
35. Deng W, Fu C, Ren X, Xia Y, Yang Y (2018) An interval precise integration method for transient unbalance response analysis of rotor system with uncertainty. Mech Syst Signal Process 107:137-148

36. Liu HM, Ouyang $\mathrm{H}$, Zhang JF, Zhang KW (2020) Stability test and dominant eigenvalues computation for second-order linear systems with multiple time-delays using receptance method. Mech Syst Signal Process 137:106180

37. Ouyang H, Chang J-Y, Tsai S-H (2020) A receptance-based method for frequency assignment via coupling of subsystems. Arch Appl Mech 90(2):449-465

38. Bathe K-J (2016) Finite Element Procedures. Prentice Hall, Pearson Education, Inc, p 1043

Publisher's Note Springer Nature remains neutral with regard to jurisdictional claims in published maps and institutional affiliations. 